\title{
Encouraging Young Pediatric Surgeons and Evaluation of the Effectiveness of a Pediatric Endosurgery Workshop by Self-assessment and an Objective Skill Validation System: The Japan-Russia Medical Cooperation Project
}

Katsuhiro Ogawa ( $\checkmark$ katsu-ogawa@oita-u.ac.jp )

Oita University Faculty Of Medicine Graduate School of Medicine: Oita Daigaku Igakubu Daigakuin Igakukei Kenkyuka

\section{Satoshi leiri}

Kagoshima University Graduate School of Medicine and Dental Sciences: Kagoshima Daigaku

Daigakuin Ishigaku Sogo Kenkyuka https://orcid.org/0000-0002-1250-093X

\section{Toshihiko Watanabe}

Tokai University School of Medicine Graduate School of Medicine: Tokai Daigaku Igakubu Daigakuin Igaku Kenkyuka

\section{Yuko Bitoh}

Kobe University Graduate School of Medicine School of Medicine: Kobe Daigaku Daigakuin Igakukei Kenkyuka Igakubu

\section{Hiroo Uchida}

Nagoya University Graduate School of Medicine Faculty of Medicine: Nagoya Daigaku Daigakuin Igakukei Kenkyuka Igakubu

\section{Atsuyuki Yamataka}

Juntendo University School of Medicine Graduate School of Medicine: Juntendo Daigaku Igakubu Daigakuin Igaku Kenkyuka

\section{Yasuharu Ohno}

Oita University Faculty Of Medicine Graduate School of Medicine: Oita Daigaku Igakubu Daigakuin Igakukei Kenkyuka

\section{Masayuki Ohta}

Oita University Faculty Of Medicine Graduate School of Medicine: Oita Daigaku Igakubu Daigakuin Igakukei Kenkyuka

\section{Masafumi Inomata}

Oita University Faculty Of Medicine Graduate School of Medicine: Oita Daigaku Igakubu Daigakuin Igakukei Kenkyuka

\section{Elena Dorofeeva}


FSBI National Medical Research Center for Obstetrics Gynecology and Perinatology named after Academician V.I.Kulakov: FGBU Naciona'Inyj medicinskij issledovatel'skij centr akuserstva ginekologii i perinatologii imeni Akademika V I Kulakova

\section{Yulia Podurovskaya}

FSBI National Medical Research Center for Obstetrics Gynecology and Perinatology named after Academician V.I.Kulakov: FGBU Naciona'Inyj medicinskij issledovatel'skij centr akuserstva ginekologii i perinatologii imeni Akademika V I Kulakova

\section{Ekaterina Yarotskaya}

FSBI National Medical Research Center for Obstetrics Gynecology and Perinatology named after Academician V.I.Kulakov: FGBU Naciona'Inyj medicinskij issledovatel'skij centr akuserstva ginekologii i perinatologii imeni Akademika $\mathrm{V}$ I Kulakova

\section{Seigo Kitano}

Oita University: Oita Daigaku

\section{Research Article}

Keywords: pediatric surgeon, endoscopic surgery, workshop, self-assessment, objective skill evaluation, international collaboration

Posted Date: February 17th, 2022

DOI: https://doi.org/10.21203/rs.3.rs-754323/v1

License: (c) (i) This work is licensed under a Creative Commons Attribution 4.0 International License. Read Full License 


\section{Abstract}

Background: Japanese pediatric endosurgery experts conducted a workshop for young pediatric surgeons in Russia in collaboration with Russian expert pediatric surgeons. This study was aimed to develop a contributive workshop program and evaluate its impact on young Russian pediatric surgeons.

Methods: A two-day pediatric endosurgery workshop was held in Russia. After conducting a needs assessment survey, Japanese and Russian faculties developed the workshop contents, including pre- and post-workshop skills assessments, lectures and hands-on training. Skills assessments were performed using the objective skill validation system, the "A-Lap Mini", mimicking intestinal anastomosis. The trainees self-evaluated their knowledge and skills using a five-point scale.

Results: Fifteen novice Russian trainees participated and 14 (93.3\%) completed the workshop. The completion rate for the suturing task before and after the workshop was 40.0\% (6/15) and 85.7\% (12/14), respectively. The following five skill evaluation criteria, which were objectively evaluated, improved: performance time changed from $751.6 \pm 247.1 \mathrm{~s}$ to $780.0 \pm 313.3 \mathrm{~s}(p>0.05)$, number of full-thickness sutures improved from $1.0 \pm 1.41$ to $2.64 \pm 0.84$ ( $p=0.003$ ), area of wound-opening changed from $0.42 \pm$ $0.83 \mathrm{~mm}^{2}$ to $0.53 \pm 1.13 \mathrm{~mm}^{2}$, suture tension improved from $55.48 \pm 19.51 \%$ to $61.95 \pm 23.91 \%(p>0.05)$, and maximum air leakage pressure improved from $3.76 \pm 2.11 \mathrm{kPa}$ to $8.42 \pm 7.68 \mathrm{kPa}(p>0.05)$.

Regarding the self-assessed questionnaire administered before and after the workshop, the confidence in endosurgery skills significantly improved as follows: forceps manipulation ability improved from 2.7 to $3.7(p<0.05)$, and suturing performance improved from 2.5 to $3.6(p<0.05)$. The usefulness of the workshop for clinical surgery was scored at 4.3.

Conclusions: Quantitative skill evaluation with an automatic feedback function was useful for endosurgery training. Delivering feedback concerning the assessment results to the trainee helps them to determine the specific training requirements needed for clinical endosurgery.

\section{Introduction}

The Japanese and Russian governments genuinely aim to contribute to medical progress in partnership with each other, through close public-private cooperation. Based on the concluded memorandum of cooperation between the two countries in 2016, the Japan-Russia medical cooperation promotion project was designed to create a virtuous cycle by extending healthy life expectancy in both Japan and Russia. As part of this project, we have signed a Memorandum of Understanding for the field of Pediatric Endosurgery with the National Medical Research Center for Obstetrics, Gynecology and Perinatology named after V.I. Kulakov in Moscow (Kulakov Center) to exchange, utilizing their mutual experience, knowledge and technology with each other.

Since 1990, the number of endoscopic surgeries, as minimally invasive surgery (MIS), has increased in Japan. In the field of pediatric surgery, endoscopic surgery (thoracoscopic surgery and laparoscopic surgery) is also becoming more common because of its minimal invasiveness, efficacy, and cosmetic 
merit. In 2017, a total of 5211 endoscopic procedures were performed for pediatric patients [1]. However, given the small number of cases and the technical complexity due to the small working space in pediatric endosurgery, in comparison to general adult endosurgery, additional care is required to ensure safety. In this background, The Japan Society for Endoscopic Surgery (JSES) has played an important role in the development of endoscopic surgery in Japan [1-3]. Notably, a technical skills certification system for surgeons, the Endoscopic Surgical Skill Qualification System (ESSQS) was established by the JSES with the aim of training instructors to provide instruction on safe and secure endoscopic surgery. In addition, the ESSQS for endoscopic technology provides a solid process for training endoscopic surgeons.

Taking advantage of this experience, Japanese pediatric endosurgery experts conducted an endoscopic surgery workshop for young pediatric surgeons in Russia in collaboration with Russian expert pediatric surgeons. The present study aimed to develop a contributive pediatric endosurgery workshop program and evaluate its impact and effectiveness among young Russian pediatric surgeons in training.

\section{Materials And Methods}

\section{Endoscopic Surgery workshop for Pediatric Surgeons}

A two-day pediatric endosurgery workshop for young pediatric surgeons was held in Russia in collaboration with the Kulakov Center in Moscow. In the 2-day workshop, the training program wasdesigned for participants to acquire sufficient basic endoscopic surgical skills and to experience advanced procedures within a short period using disease-specific simulators. The trainingschedule is shown in Table 1. The workshop included pre- and post-workshop skills evaluation, mini-lectures regarding basic endoscopic surgical skills and clinical procedures, and hands-on training, including basic skills (needle handling, needle adjustment, needle driving, square knot, surgeon's knot and slip knot techniques) and advanced skill training using disease specific simulators. 
Table 1

The 2-day workshop training schedule

Day I Day 2

\begin{tabular}{ll}
$\begin{array}{l}\text { Time } \\
\text { course }\end{array}$ & Training menu \\
\hline 9:30- & Lecture: Brief introduction of the Simulation \\
10:00 & Training Center
\end{tabular}

10:00 - Lecture: Overview of Pediatric MIS in Russia $10: 40$
10:40 Lecture: Basic principles in endoscopic surgery
\& Ergonomics in MIS

$11: 00$

11:00- Pre-training skill evaluation
$11: 45$

\section{1:45- Fundamental endoscopic skills Hands-on: \\ 13:00 Needle handling, Needle adjustment, Square knot, Surgeon's knot, \\ Slip knot, Extracorporeal knot tying}

$\begin{array}{lll}\text { 13:00- Lunch } & 13: 00- & \text { Video lecture: Pediatric } \\ \text { 14:00 } & 13: 30 & \text { Robotic Procedure }\end{array}$

14:00 - Lecture: Basic and Clinical Research for

14:20 Pediatric Congenital Disease

13:30- Hands-on: Advanced

15:30 technique and Diseasespecific simulator experience

Diaphragmatic hernia, Esophageal atresia

Choledochal cyst.

14:20 Lecture: Congenital kidney Anomalies:

- Diagnostics and Treatment

$14: 40$
14:40 Lecture: Pediatric Tracheal Disease and - Treatment

$15: 00$

$\begin{array}{llll}\text { 15:00- } & \text { Hands-on: Tracheal Scope and Fundamental } & 16: 00- & \text { Feedback of the day and } \\ \text { 16:30 } & \text { Endoscopic Skills } & 16: 30 & \text { Post-workshop questionnaire }\end{array}$

※MIS: Minimally Invasive Surgery

A total of 15 young Russian pediatric surgeons participated in this workshop. The faculty group consisted of 9 expert pediatric surgeons (7 surgeons were Japanese and 2 surgeons were Russian) who were licensed as a specialist or supervising doctor of pediatric surgery in their respective countries. In the 
hands-on training, trainees were divided into four groups and each group had more than two faculties. Each group had an endoscopic surgery training box and simulators for pediatric surgery, as shown in Figure 1. These simulators included thoracoscopic and laparoscopic repair for congenital diaphragmatic hernia, thoracoscopic end-to-end anastomosis for esophageal atresia (Figure 1a), and laparoscopic hepaticojejunostomy for congenital biliary dilation (KYOTO KAGAKU Co. LTD, Kyoto, Japan and SUNARROW LIMITED, Tokyo, Japan) (Figure 1b).

The endoscopic surgery skill assessments were performed using the objective endoscopic surgical skill validation system "A-Lap Mini" (KYOTO KAGAKU Co. LTD) mimicking intestinal anastomosis. The total hands-on training time was 5.5 hours. Japanese and Russian faculties developed the contents of the workshop based on a needs assessment survey of young pediatric surgeons in Russia.

\section{The pre- and post-workshop assessment questionnaires}

All trainees completed the self-assessment questionnaire before and after the workshop. The preworkshop assessment questionnaires consisted of four categories, Personal information, Current status of endoscopic surgery, Need for endoscopic surgery, Barriers to endoscopic surgery. This questionnaire surveyed the experiences and ideas of trainees in relation to endoscopic surgery. The post-workshop assessment questionnaire was a satisfaction survey. After the workshop, the trainee also performed a self-evaluation, using a five-point scale, of their knowledge and skills in relation to the endoscopic surgery.

\section{The pre- and post-workshop skill evaluation}

The endoscopic surgery skill assessment system that was used in the workshop, the A-Lap Mini, is shown in Figure 2a. Each trainee performed a suturing task that involved wound closure with three sutures mimicking intestinal anastomosis. The model consisted of mucosal, submucosal, muscle and serosal layers. The time taken to complete the task was also recorded (Figure $2 b, 2 c)$. The suturing skills assessments were performed using internal air pressure measurements and an image analysis. The system utilizes five criteria (time taken, air pressure leakage, full-thickness suture, suture tension and opening area of the wound) to evaluate endoscopic suturing skills. For each result, feedback on the objective and quantitative skill assessments was immediately provided during the workshop (Figure. 2d).

\section{Statistical analysis}

The quantification of the assessment questionnaires and skill assessment in this study were compared before and after the workshop, statistically. The data were analyzed using the Mann-Whitney U test and $\chi^{2}$ test. All statistical analyses were performed using the JMP software program (version 14.2, SAS Institute, Cary, NC, USA). $P$ values of $<0.05$ were considered to indicate statistical significance.

\section{Results}


The pre-workshop assessment questionnaires

Results of the pre-workshop assessment questionnaires were shown in Table 2. Fifteen Russian trainees who were novice pediatric surgeons (mean age: 28 years) and 9 faculty members (7 Japanese and 2 Russians) participated in this workshop. Fourteen (93.3\%) trainees completed the 2-day workshop. The male-to-female ratio was 9: 6, with 9 pediatric surgeons $(60 \%)$ who were residents within 2 years of becoming a medical doctor. Only three trainees (20.0\%) had experienced more than 100 endoscopic surgery cases, the others had experienced $<50$ endoscopic surgery cases. While most trainees were confident in handling the scope $(3.27 \pm 1.18)$, they had low confidence in their endoscopic surgical skills, including suturing $(2.53 \pm 1.08)$. The majority of trainees felt that endoscopic surgery had more advantages than open procedures $(4.27 \pm 1.06)$, and strongly felt the necessity to acquire training in endoscopic surgical skills and knowledge (4.53 \pm 1.09$)$. 
Table 2

The pre-workshop assessment questionnaires

\section{The pre-workshop assessment questionnaires (\%)}

\section{Respondents}

Age

Sex (Male: Female)

$9 / 6$

Appointment

Professor

$0(0)$

Associate Professor

$0(0)$

Lecturer

$0(0)$

Assistant Professor

$0(0)$

Senior consultant

$3(20)$

Consultant

1(6.7)

Fellow

2

Resident

$9(60)$

Type of hospital

Medical college teaching hospital

2(13.3)

Government hospital

7(46.7)

Private general hospital

$0(0)$

Specialized children's hospital

$6(40)$

Experience in endosurgery procedures

0

$1(6.7)$

$1-10$

$4(26.7)$

$11-50$

7(46.7)

$51-100$

$0(0)$

$>101$

$3(20)$

Endosurgical operations performed in their hospitals in last 1 year

$\begin{array}{ll}0 & 0(0) \\ 1-10 & 4(26.7) \\ 11-50 & 2(13.3) \\ 51-100 & 1(6.7) \\ >101 & 8(53.3)\end{array}$


The pre-workshop assessment questionnaires (\%)

Confidence in endoscopic surgical skills

\begin{tabular}{ll} 
Suturing & $2.53 \pm$ \\
& 1.08 \\
\hline Dissection & $3.00 \pm$ \\
& 1.10 \\
\hline Using energy-based devices & $2.93 \pm$ \\
& 1.12 \\
\hline Handling Scope & $3.27 \pm$ \\
& 1.18 \\
\hline Port insertion & $3.00 \pm$ \\
& 1.10 \\
\hline Overall & $2.73 \pm$ \\
\end{tabular}

*Responses are on a 5-point Likert-type scale ranging from 1 (not confident at all) to 5 (very confident)

The advantages of endoscopic surgery in comparison to open surgery

\begin{tabular}{ll} 
Decreased wound infection & $4.07 \pm$ \\
& 1.12 \\
\hline Decreased blood loss & $4.07 \pm$ \\
& 1.12 \\
\hline Reduced postoperative pain & $4.47 \pm$ \\
& 1.19 \\
\hline Reduced postoperative & $4.33 \pm$ \\
hospitalization length & 1.19 \\
\hline As a diagnostic tool (Exploratory & $4.20 \pm$ \\
laparoscopy) & 1.17 \\
\hline overall & $4.27 \pm$ \\
& 1.06
\end{tabular}

*Responses are on a 5-point Likert-type scale ranging from 1 (disagree) to 5 (agree)

Need for training in endoscopic surgical skills and Suturing $4.40 \pm$ knowledge

\begin{tabular}{ll|} 
Suturing & $4.40 \pm$ \\
& 1.08 \\
\hline Dissection & $4.33 \pm$ \\
& 1.19 \\
\hline Using energy-based devices & $4.06 \pm$ \\
& 1.24 \\
\hline Handling Scope & $4.13 \pm$ \\
& 1.20 \\
\hline Basic knowledge & $4.13 \pm$ \\
& 1.25
\end{tabular}


The pre-workshop assessment questionnaires (\%)

Overall

*Responses are on a 5-point Likert-type scale ranging from 1 (unnecessary) to 5 (necessary)

The post-workshop assessment questionnaires

The results of the post-workshop assessment questionnaires are shown in Table 3. We gave 17 minilectures over approximately 6 hours regarding basic endoscopic surgical skills and clinical procedures over two days, and the trainees assessed the lectures very highly as follows: basic principles in endoscopic surgery, $4.57 \pm 0.73$; fundamental endoscopic skills with demonstration, $4.93 \pm 0.26$; and advanced technique and disease-specific simulator experience with a video lecture, $4.86 \pm 0.35$. Among the disease-specific simulators, trainees seemed to have more difficulty in duodenal atresia $(1.86 \pm 0.74)$ and hepaticojejunostomy of congenital biliary dilation $(1.71 \pm 0.80)$ because they had difficulty with the fundamental hands-on endoscopic skills, such as needle handing ( $2.57 \pm 0.98)$, needle adjustment (2.79 $\pm 0.94)$, and knot tying $(2.79 \pm 1.01)$. Therefore, the hands-on tasks received a high assessment of $\geq 4.5$ in relation to their usefulness for actual endoscopic surgery.Regarding the self-assessed questionnaires administered before and after the workshop, the confidence in endoscopic surgery skills significantly improved as follows: forceps manipulation ability improved from 2.7 to $3.7(p<0.05)$, and suturing performance improved from 2.5 to $3.6(p<0.05)$. The usefulness of the workshop for clinical surgery was scored at 4.3 (Table 4). 


\section{Assessment of lecture}

The basic principles in endoscopic surgery

$4.57 \pm 0.73$

Fundamental endoscopic skills: Demonstration and Mini Lecture

$4.93 \pm 0.26$

Advanced technic and Disease-specific simulator experience: Video lecture

$4.86 \pm 0.35$

*Responses are on a 5-point Likert-type scale ranging from 1 (not useful at all) to 5 (very useful) Difficulty of hands-on

Needle handing

$2.57 \pm 0.98$

Needle adjusting

$2.79 \pm 0.94$

Knot tying

$2.79 \pm 1.01$

Diaphragmatic hernia

$2.14 \pm 0.91$

Duodenal atresia

$1.86 \pm 0.74$

Esophageal atresia

$2.21 \pm 0.86$

Congenital biliary dilation

$1.71 \pm 0.80$

*Responses are on a 5-point Likert-type scale ranging from 1 (very difficult) to 5 (very easy) Tasks of hands-on usefulness for actual surgery

Needle handing $4.43 \pm 0.82$

Needle adjusting $4.50 \pm 0.82$

Knot tying $4.61 \pm 0.59$

Diaphragmatic hernia $4.57 \pm 0.73$

Duodenal atresia

$4.64 \pm 0.72$

Esophageal atresia

$4.57 \pm 0.82$

Congenital biliary dilation

$4.57 \pm 0.82$

*Responses are on a 5-point Likert-type scale ranging from 1 (not useful at all) to 5 (very useful)

Sufficient equipment and time to practice the task

Fundamental endoscopic skills

Equipment

$4.07 \pm 1.06$ 


\begin{tabular}{|cc|}
\hline & Response, Mean \\
\hline Time & $3.57 \pm 1.35$ \\
\hline Advanced technique and disease-specific simulator experience & \\
\hline Equipment & $4.07 \pm 1.06$ \\
\hline Time & $3.50 \pm 1.30$ \\
\hline
\end{tabular}

Table 4

Results of the skill evaluation and self- assessment questionnaire

\begin{tabular}{|c|c|c|c|}
\hline & Pre-workshop & Post-workshop & $p$ value \\
\hline \multicolumn{4}{|l|}{ Skill evaluation } \\
\hline Completion rate of suturing task (\%) & $35.7(5 / 14)$ & $92.9(13 / 14)$ & 0.001 \\
\hline Performance time (sec) & $751.6 \pm 247.1$ & $780.0 \pm 313.3$ & 0.882 \\
\hline Number of Full-thickness suture & $1.0 \pm 1.41$ & $2.64 \pm 0.84$ & 0.003 \\
\hline Area of wound-opening $\left(\mathrm{mm}^{2}\right)$ & $0.42 \pm 0.83$ & $0.53 \pm 1.13$ & 0.828 \\
\hline Suture tensions (\%) & $55.48 \pm 19.51$ & $61.95 \pm 23.91$ & 0.349 \\
\hline Maximum air leakage pressure $(\mathrm{kPa})$ & $3.76 \pm 2.11$ & $8.42 \pm 7.68$ & 0.323 \\
\hline \multicolumn{4}{|c|}{ Confidence in endoscopic surgery skills (Self-assessed questionnaire, 5-point scale) } \\
\hline Forceps manipulation ability & 2.7 & 3.7 & 0.003 \\
\hline Suturing performance & 2.5 & 3.6 & 0.006 \\
\hline Usefulness of workshop & - & 4.3 & \\
\hline
\end{tabular}

\section{Five criteria for skill assessment and measurements using A-Lap}

The results of the 5 criteria for skill assessment and measurements using A-Lap Mini are shown in Table 4. The completion rate of the suturing task before and after the workshop was $35.7 \%(5 / 14)$ and $92.9 \%$ $(13 / 14)$, respectively, which was statistically significant $\left(\chi^{2}(1)=9.956, p=0.001\right)$. The five skill evaluation criteria that were used as an objective evaluation for the 14 participants who performed tasks before and after the workshop changed as follows: performance time changed from $751.6 \pm 247.1 \mathrm{sec}$ to $780.0 \pm 313.3 \mathrm{sec}(p>0.05)$, number of full thickness sutures improved from $1.0 \pm 1.41$ to $2.64 \pm 0.84$ ( $p$ $=0.003)$, area of wound-opening changed from $0.42 \pm 0.83 \mathrm{~mm}^{2}$ to $0.53 \pm 1.13 \mathrm{~mm}^{2}(p>0.05)$, suture tension changed from $55.48 \pm 19.51 \%$ to $61.95 \pm 23.91 \%(p>0.05)$, and maximum air leakage pressure changed from $3.76 \pm 2.11 \mathrm{kPa}$ to $8.42 \pm 7.68 \mathrm{kPa}(p>0.05)$. 


\section{Discussion}

We conducted a 2-day pediatric endosurgery workshop for young pediatric surgeons in Russia in collaboration with Russian expert pediatric surgeons using a self-assessment questionnaire survey and objective skill validation system. The major findings of this study were as follows: (1) Pre-workshop assessment questionnaires revealed that young Russian pediatric surgeon strongly felt the need to acquire knowledge and training in endoscopic surgical skills and had low confidence in their endoscopic surgical skills, such as suturing. (2) Regarding the endoscopic surgery skill evaluation task using the ALap Mini, the completion rate of the suturing task and the number of full thickness sutures were significantly improved after the workshop. (3) The post-workshop assessment questionnaires revealed that they valued the contents of the workshop, such as basic principles in endoscopic surgery, fundamental endoscopic skills with demonstration, and the advanced technique and disease-specific simulator experience with video lectures. On the other hand, they felt more difficulty for performing the disease specific simulators. (4) young Russian pediatric surgeon had the confidence in endoscopic surgery skills significantly improved after workshop regarding forceps manipulation ability and suturing performance. They also evaluated the usefulness of the workshop for clinical surgery.

Although endoscopic surgery has the advantage of being less invasive than open surgery, it involves highly difficult techniques, which must be performed from a limited direction under a monitor using only limited instruments. With the widespread use of endoscopic surgery, many complications have been reported $[4,5]$; however, many of these are due to the absence of an appropriate training program, which would facilitate the acquisition of skills needed to perform endoscopic surgery safely [6]. To acquire skills in endoscopic surgery, reading textbooks and watching videos of clinical cases are not sufficient; handson training is absolutely essential. Under these circumstances, the Japan Society for Endoscopic Surgery established the world's first ESSQS [7, 8]. Certification examinations started in 2003 for obstetrics and gynecology, in 2004 for gastroenterology and general surgery, urology, orthopedics, and in 2008 for pediatric surgery. The accredited doctor system certifies that the acquirer "has the surgical skills to safely and properly perform endoscopic procedures and has the ability to provide direction and guidance." Japanese surgeons have endeavored to improve their endoscopic surgical skills and to train young surgeons through various activities, such as the establishment of the ESSQS, the provision of educational seminars, and the development of the Practice Guidelines on Endoscopic Surgery [9],

Based on this knowledge and sufficient experience in the development of educational systems that facilitate the acquisition of endoscopic surgery techniques in Japan, we held a hands-on seminar for young Russian pediatric surgeons this time. The content of this seminar was designed to not only provide knowledge in relation to endoscopic surgery through the lectures of experts, but also to use the diseasespecific simulators brought from Japan to improve endoscopic surgery skills. The A-Lap Mini was developed to provide an objective assessment of the performance of the suture ligature method in intestinal anastomosis [10]. This system can automatically indicate not only the examinee's skills and weak points but also expert skill levels. Using this system, novice surgeons can recognize their skill levels and the differences of expert surgeons. They can also establish skill endpoints. 
In this study, by evaluating the participants themselves before and after the workshop, we provided not only specific feedback on suturing techniques, but also the strong and weak points of each trainee. In fact, the two-day workshop was able to significantly improve the completion rate of the suturing task and number of full-thickness sutures. Furthermore, the area of wound-opening, suture tension and the maximum air leakage pressure tended to be improved, although these differences were not statistically significant. This means that loosening of the ligature disappeared due to improvement in the suturing technique. However, the training delivered in the 2-day workshop did not lead to a significant improvement in laparoscopic forceps skills, such as the performance time. Short-term training contributes to the improvement of skill acquisition, but does not improve skill quality $[11,12]$. Continuous training is most important for performing safe, secure and high-quality endoscopic surgery.

Differences in surgical skill between expert surgeons and novice surgeons appear in the difference in their forceps handling during endoscopic surgery [13], it seems that considerable time and experience are required to improve a surgeon's forceps handling. In a study examining the relationship between quick forceps handling and surgical performance [14], rough and quick handling of the forceps is associated with creating more organ damage, but not faster performance. In short, slow manipulation of the forceps ("zero" speed of acceleration) results in the performance of safe and secure endoscopic surgery in comparison to rough and quick manipulation of the forceps. This is a very important factor and a matter to be kept in mind, especially in pediatric endosurgery performed in small working spaces.

In addition, we also brought in a disease specific model of pediatric endosurgery from Japan for training. Since Satava et al. [15] pointed out the usefulness of simulators for endoscopic surgical training in 1993, many different types of simulators have been developed and their clinical application has been reported [16]. Recently, three-dimensional models of organs produced by 3D printing have become more popular [17]. In the pediatric endosurgery field, there is evidence that simulator training is a highly effective educational modality $[18,19]$. However, there are very few simulators dedicated to pediatric endosurgery, and it is difficult to say whether sufficient training can be gained due to the lower number of cases. In this study, using a simulator developed by a Japanese company for pediatric surgery, we were able to give the trainees a taste of the difficulties of operating in the small working space unique to children. The objective evaluation of the suturing technique, which allowed the participants to understand their own weaknesses and to experience a disease simulator for pediatric endosurgery, is believed to have contributed to the satisfaction of the participants in this workshop.

The present study was associated with some limitations. We did not investigate whether the results of this workshop were correlated with subsequent clinical outcomes. This requires an objective evaluation by a similar simulator six months or several years later. The objective assessment of surgical performance and the provision of feedback are important processes for conducting effective training [20]. These can give trainees a sense of improvement in their own surgical skills and may give them confidence. Successful surgery requires the smooth integration of different skills and this requires further training and assessment. We need to strive to hold these workshops on a regular basis. 


\section{Conclusion}

In our efforts to develop an effective pediatric endosurgery workshop program, we learned that a needs assessment survey based on trainee experiences and a feedback system were important for motivating young pediatric surgeons in training. A quantitative skill evaluation with an automatic feedback function is a useful tool for endoscopic surgery training. Delivering feedback on the assessment results to the trainee helps them determine their specific training requirements for clinical endoscopic surgery.

\section{Declarations}

\section{Ethics approval and consent to participate}

The trainees gave informed consent and voluntarily agreed to participate in this study. This workshop performed in accordance with the ethical standards of the institutional and national research committee. Individual information and obtained data were anonymized. The study design was judged to be unnecessary for reviewing and approval by an ethical board at both Japanese and Russian institution.

\section{Consent for publication}

Not applicable.

\section{Availability of data and materials}

All data generated or analysed during this study are included in this published article.

\section{Competing interests}

The authors declare that they have no conflicts of interest or financial ties to disclose.

\section{Funding}

This research received no funds.

\section{Authors' contributions}

$\mathrm{KO}, \mathrm{SI}, \mathrm{TW}, \mathrm{YB}, \mathrm{HU}, \mathrm{AY}, \mathrm{YO}, \mathrm{ED}, \mathrm{YP}, \mathrm{EY}$, and SK participated in this workshop as faculties. KO drafted the manuscript. SI reviewed the manuscript. All persons who meet authorship criteria are listed as authors, and all authors certify that they have participated sufficiently in the work to take public responsibility for the content, including participation in the concept, design, analysis, writing, and revision of the manuscript.

\section{Acknowledgements}

This project has been conducted with the cooperation of Asian Medical Education and Training Support, AMETS. The authors would like to express gratitude to Miho Sato from Oita University and Yumiko Hirota, 
Shinichiro Watanabe, Saori Imani from Oita University Research Promotion Division. We would like also to thanks trainees of young Russian pediatric surgeons for their participation in this study. We could not have completed the survey study without their support.

\section{References}

1. Inomata M, Shiroshita H, Uchida H, Bandoh T, Akira S, Yamaguchi S, et al. Current status of endoscopic surgery in Japan: The 14th National Survey of Endoscopic Surgery by the Japan Society for Endoscopic Surgery. Asian J Endosc Surg. 2020;13:7-18.

2. Bandoh T, Shiraishi N, Yamashita Y, Terachi T, Hashizume M, Akira S, et al. Endoscopic surgery in Japan: The 12th national survey(2012-2013) by the Japan Society for Endoscopic Surgery. Asian J Endosc Surg. 2017: 10:345-53.

3. Shiroshita H, Inomata M, Bandoh T, Uchida H, Akira S, Hashizume M, et al. Endoscopic surgery in Japan: The 13th national survey (2014-2015) by the Japan Society for Endoscopic Surgery. Asian J Endosc Surg. 2019;12::7-18.

4. Shettko DL. Complications in laparoscopic surgery. The Veterinary clinics of North America Equine practice. 2000; 16:377-383, vii-viii.

5. Han NY, Sung DJ, Park BJ, Kim MJ, Cho SB, Kim YH. Imaging of complications associated with port access of abdominal laparoscopic surgery. Abdom Imaging. 2014;39(2):398-410.

6. Xu T, Makary MA, Al Kazzi E, Zhou M, Pawlik TM, Hutfless SM. Surgeon-Level Variation in Postoperative Complications. J Gastrointest Surg. 2016;20(7):1393-9.

7. Mori T, Kimura T, Kitajima M. Skill accreditation system for laparoscopic gastroenterologic surgeons in Japan. Minim Invasive Ther Allied Technol. 2010;19::18-23.

8. Akagi T, Endo H, Inomata M, Yamamoto H, Mori T, Kojima K, et al. Clinical impact of Endoscopic Surgical Skill Qualification System (ESSQS) by Japan Society for Endoscopic Surgery (JSES) for laparoscopic distal gastrectomy and low anterior resection based on the National Clinical Database (NCD) registry. Ann Gastroenterol Surg. 2020;4::721-34.

9. Sakai Y, Kitano S. Practice Guidelines on Endoscopic Surgery for qualified surgeons by the Endoscopic Surgical Skill Qualification System. Asian J Endosc Surg. 2015;8:103-13.. ; .:

10. Uemura M, Yamashita M, Tomikawa M, Obata S, Souzaki R, leiri S, et al. Objective assessment of the suture ligature method for the laparoscopic intestinal anastomosis model using a new computerized system. Surg endosc. 2015;29::444-52.

11. leiri S, Nakatsuji T, Higashi M, Akiyoshi J, Uemura M, Konishi K, et al. Effectiveness of basic endoscopic surgical skill training for pediatric surgeons. Pediatr Surg Int. 2010;26::947-54.

12. Tanoue K, leiri S, Konishi K, Yasunaga T, Okazaki K, Yamaguchi S, et al. Effectiveness of endoscopic surgery training for medical students using a virtual reality simulator versus a box trainer: a randomized controlled trial. Surg Endosc. 2008;22::985-90. 
13. Uemura M, Tomikawa M, Kumashiro R, Miao T, Souzaki R, leiri S, et al. Analysis of hand motion differentiates expert and novice surgeons. J Surg Res. 2014;188:8-13.

14. Kengen B, IJgosse WM, van Goor H, Luursema JM. (2020) Fast or safe? The role of impulsiveness in laparoscopic simulator performance. Am J Surg. 2020; 220: 914-9.

15. Satava RM. Virtual reality surgical simulator. The first steps. Surg endosc. 1993;7:203-5.

16. Dawe SR, Pena GN, Windsor JA, Broeders JA, Cregan PC, Hewett PJ, et al. Systematic review of skills transfer after surgical simulation-based training. Br J Surg. 2014;101:1063-76.

17. Furukawa J, Miyake H, Tanaka K, Sugimoto M, Fujisawa M. Console-integrated real-time threedimensional image overlay navigation for robot-assisted partial nephrectomy with selective arterial clamping: early single-centre experience with 17 cases. Int J Med Robot. 2014;10:385-90.

18. Cheng A, Lang TR, Starr SR, Pusic M, Cook DA. Technology-enhanced simulation and pediatric education: a meta-analysis. Pediatrics. 2014;133::e1313-23.

19. Yokoyama S, Mizunuma K, Kurashima Y, Watanabe Y, Mizota T, Poudel S, et al. Evaluation methods and impact of simulation-based training in pediatric surgery: a systematic review. Pediatr Surg Int. 2019;35:1085-94.

20. Yamaguchi T, Nakamura R. Laparoscopic training using a quantitative assessment and instructional system. Int J Comput Assist Radiol Surg. 2018;13:1453-61.

\section{Figures}




\section{Figure 1 Disease specific simulators}
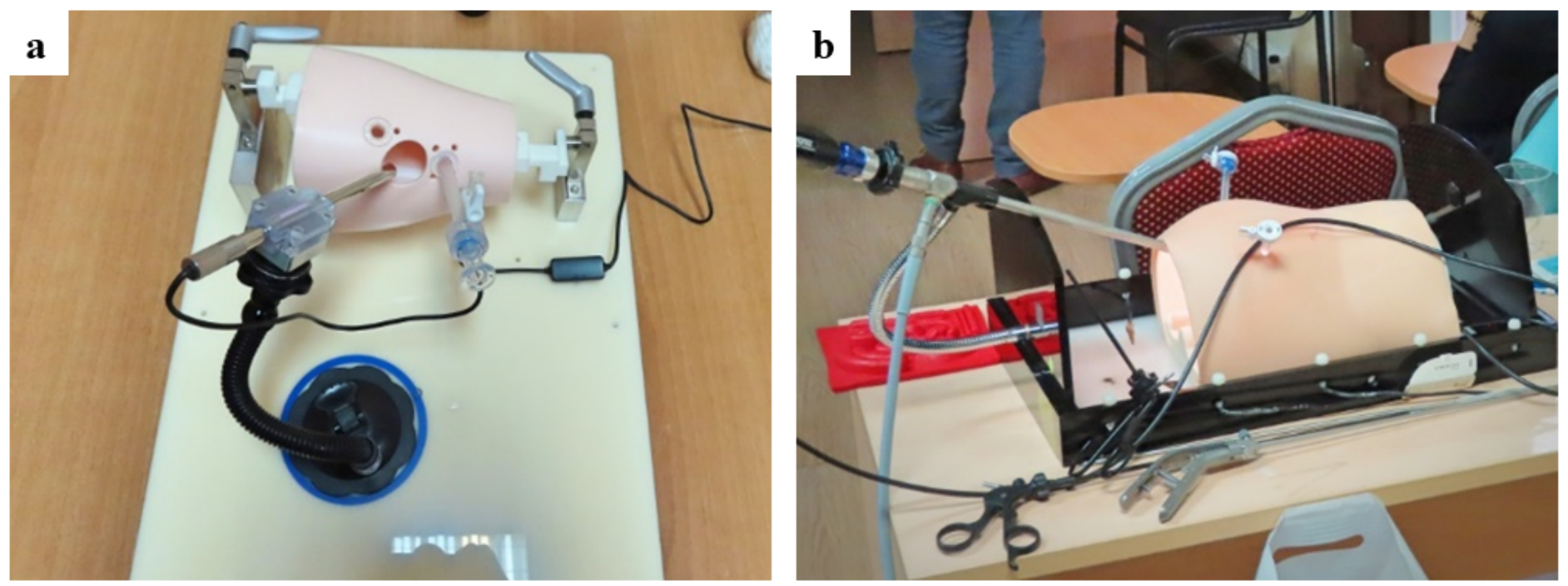

Figure 1

Disease specific simulators

a: Simulator for esophageal atresia

b: Simulator congenital biliary dilation. 


\section{Figure 2 The endoscopic surgical skill evaluation system "A Lap"}
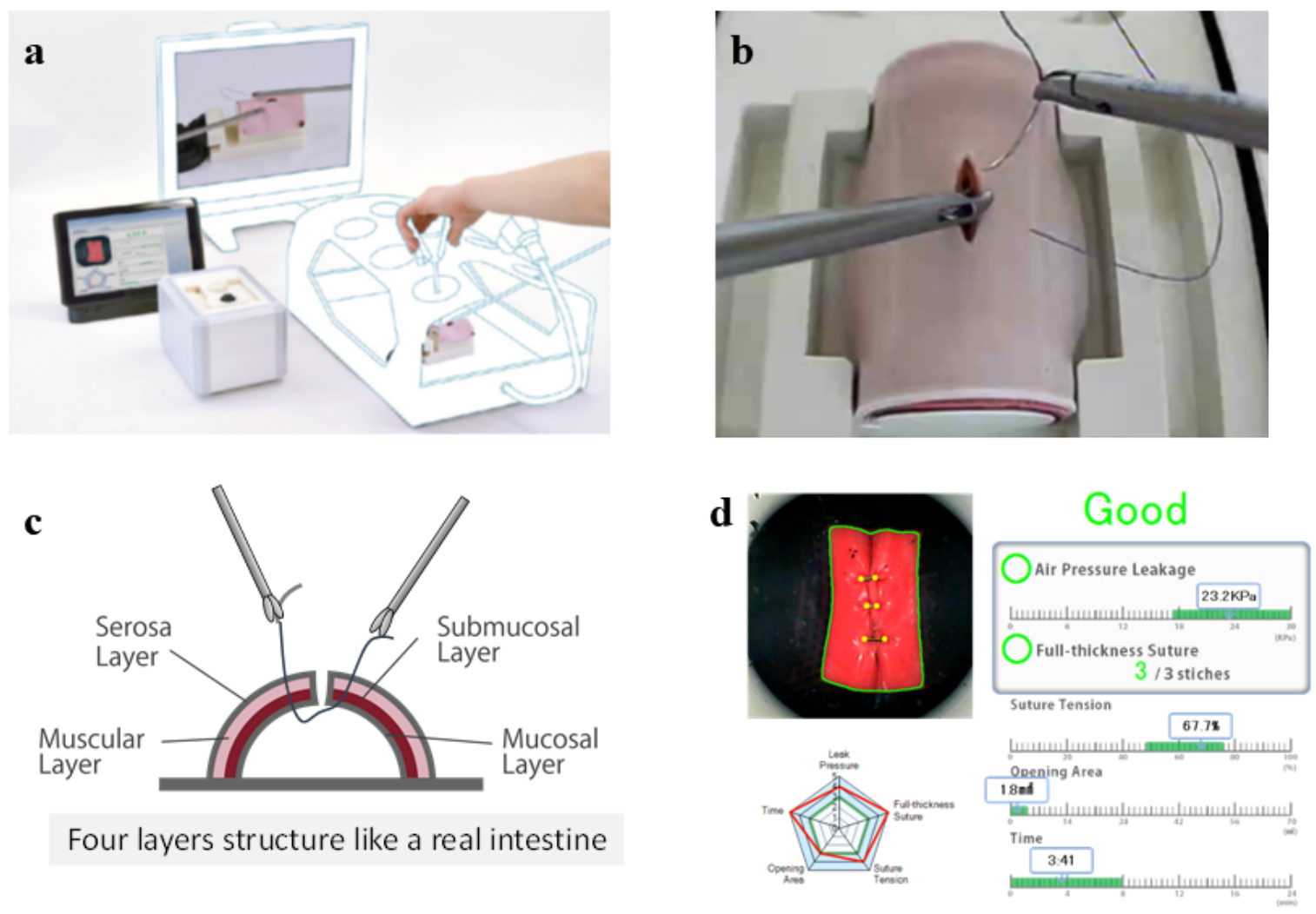

Figure 2

Four layers structure like a real intestine

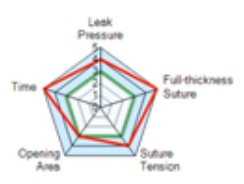

\section{The endoscopic surgical skill evaluation system "A Lap"}

a: A Lap is consisting of suturing model, internal air pressure measurements and an image analysis device and $\mathrm{PC} /$ Tablet. Suturing model is used in training box.

b, c: The model consisted of mucosal, submucosal, muscle and serosal layers.

$\mathrm{d}$ : The suturing skills assessments were performed using internal air pressure measurements and an image analysis. The system utilizes five criteria (time taken, air pressure leakage, full-thickness suture, suture tension and opening area of the wound) to evaluate endoscopic suturing skills. 